\title{
次大风子素酰胺类衍生物的合成及抗癌活性评价
}

\author{
力瓦衣丁 - 买合苏提 ${ }^{a, c}$ 於俊杰 ${ }^{b}$ 王 琪 ${ }^{b}$ \\ 曹建国*, 黄国正 $*, a, b$ \\ $\left({ }^{a}\right.$ 中国科学院新疆理化技术研究所 干旱区植物资源与化学重点实验室 乌鲁木齐 830011) \\ $\left({ }^{b}\right.$ 上海师范大学生命科学学院 上海 201418) \\ ( ${ }^{c}$ 中国科学院大学 北京 100049)
}

\begin{abstract}
摘要 大风子素是一类自然界稀有的黄酮木质素类化合物, 因其稀有, 至今对它的结构修饰和活性研究较少. 以廉价 易得的水飞蓟素为原料, 合成了 C- 23 位碘代的次大风子素. 再经过叠氮化、还原和酰胺化, 得到了 15 个次大风子素的 酰胺类衍生物. 应用三种人癌细胞对这些化合物进行了初步的抗癌活性评价, 结果显示部分化合物对人非小细胞肺癌 细胞(A549)具有良好的增值抑制活性, 其半数抑制浓度 $\left(\mathrm{IC}_{50}\right)$ 均小于 $10 \mu \mathrm{mol} \cdot \mathrm{L}^{-1} ; 23-(3,4-$ 二甲氧基苯甲酰胺基)次大风 子素(6b)和 23-(2-氯-6-氟苯甲酰胺基)次大风子素(6f)对于人宫颈癌细胞(HeLa)显示出了较好的抑制活性; 23-(4-氟苯甲 酰胺基)次大风子素 $(\mathbf{6 g}$ )和 23-[3,5-双 (三氟甲基)苯甲酰胺基]次大风子素(6m)则对人乳腺癌细胞(MCF-7)具有良好的抑制 活性. 这些结果表明, 这类化合物对正常肝细胞毒性较小, 而对癌细胞增殖有一定抑制作用, 值得深入研究以开发新 型抗癌药物.
\end{abstract}

关键词 次大风子素; 水飞薊素; 结构衍生; 抗癌活性

\section{Synthesis and Anticancer Evaluation of Amido-Derivative of Hydnocarpin D}

\author{
Maihesuti, Liwaliding ${ }^{a, c} \quad$ Yu, Junjie ${ }^{b} \quad$ Wang, Qi $^{b}$ \\ Cao, Jianguo ${ }^{*, b} \quad$ Huang, Guozheng ${ }^{*, a, b}$ \\ $\left({ }^{a}\right.$ Key Laboratory of Plant Resources and Chemistry of Arid Zone, Xinjiang Technical Institute of \\ Physics and Chemistry, Chinese Academy of Sciences, Urumqi 830011) \\ ( ${ }^{b}$ College of Life Sciences, Shanghai Normal University, Shanghai 201418) \\ ( ${ }^{c}$ University of Chinese Academy of Sciences, Beijing 100049)
}

\begin{abstract}
Hydnocarpins are a rare type of flavonoligan compounds occurring in nature. Because of their rarity, only a few research has been devoted on their structural modification and activity. In this work, 23-iodo hydnocarpin D was synthesized from silibinin, which is cheap and commericially available. After azidation, reduction and amidation, 15 amido-derivatives of hydnocarpin D were obtained. These compounds with regard to their anticancer activities were evaluated on three kinds of human cancer cells, and the results showed that some compounds are active on $\mathrm{A} 549$ with $\mathrm{IC}_{50}$ values less than $10 \mu \mathrm{mol} \cdot \mathrm{L}^{-1}$. 23-(3,4-Dimethoxybenzamido)hydnocarpin D (6b) and 23-(2-chloro-4-fluorobenzamido)hydnocarpin D (6f) can strongly inhibit the growth of HeLa cells. 23-(4-Fluorobenzamido)hydnocarpin D (6g) and 23-[3,5-bis(trifluoromethyl)benzamido]hydnocarpin D $(6 \mathbf{m})$ showed potent activity against MCF-7 cells. These preliminary results testified that the synthsis of amido-derivative of hydnocarpin $\mathrm{D}$ could be an option for the development of new anti-cancer drug candidates.
\end{abstract}

Keywords hydnocarpin D; silibinin; structural modification; anticancer activity

黄酮木质素是黄酮和苯丙素(木质素)结合形成的一 类化合物. 最早分离出的黄酮木质素是水飞蓟宾(silybin or silibinin). 水飞蓟宾包含一对非对映异构体：水飞蓟
宾 A (1a) 和水飞蓟宾 B (1b, 图 1), 它们主要是从水飞 蓟(Silybum marianum (L.) Gaertn.)果实的标准提取物水 飞蓟素(silymarin)中分离出来的, 是水飞蓟素的主要成

\footnotetext{
* Corresponding authors. E-mail: guozheng.huang@yahoo.com; cao101@shnu.edu.cn

Received April 21, 2020; revised June 10, 2020; published online July 15, 2020.
} 
分. 水飞蓟宾是保肝药物利肝隆 $\left(\right.$ Legalon $\left.^{\circledR}\right)$ 的主要活性 成分. 这种药物对慢性肝炎、酗酒引起的肝损伤以及鬼 笔鹅亳菌引起的中毒有较好的疗效 ${ }^{[1-2]}$. 水飞蓟宾也具 有较好的抗氧化活性、抗甲流感病毒和抗癌活性 ${ }^{[3-5]}$. 水 飞蓟宾 $\mathrm{A}$ 和水飞蓟宾 $\mathrm{B}$ 在自然界中以约 $1: 1$ 的混合物 的形式存在. 虽然早在 1968 年就已开始了对水飞蓟宾 的分离, 但是由于较难纯化, 直到 2003 年 Kim 等 ${ }^{[6]}$ 通过 对比模型化合物 3-甲基-2-苯基-1,4-苯并二氧六环与水 飞蓟宾的圆二色光谱( $\mathrm{CD}$ 谱), 确定了水飞蓟宾 $\mathrm{A}(\mathbf{1 a})$ 的 手性为 $2 R, 3 R, 10 R, 11 R$, 水飞薊宾 $\mathrm{B}(\mathbf{1 b})$ 的手性为 $2 R, 3 R, 10 S, 11 S$, 人们才最终确认水飞蓟宾的绝对构型. 因为水飞蓟宾具有广泛的活性且容易从自然资源中获 得, 对水飞蓟宾及其衍生物的研究也比较多 ${ }^{[7]}$.

与水飞蓟宾结构类似的另一类黄酮木质素类化合 物是大风子素. 它们从结构上可以看作是将水飞蓟宾 3 位的羟基与 2 位氢脱水形成 2,3 位双键的产物. 代表性 的化合物包括首次由 Guz 和 Stermitz ${ }^{[8]}$ 合成之后又从 Hydnocarpus wightiana 分离得到的次大风子素(3, 图 1, 也称作大风子素 $\mathrm{D})^{[9]}$, 以及同样从 $H$. wightiana 分离得 到的大风子素 (Hydnocarpin, 2), Hydnowightin (4) 和 Neohydnocarpin (5) ${ }^{[10-12]}$. 根据报道, 大风子素 (2) 和 neohydnocarpin (5)对于白血病 $\mathrm{Tmolt}_{3}$ 细胞增长有显著 抑制作用 ${ }^{[13]}$. 大风子素(2)具有自由基清除作用 ${ }^{[14]}$ 和体 外抑制金黄色葡萄球菌 NorA 的多药耐药性外排㬌作 用 ${ }^{[15]}$. 另外 5-甲氧基大风子素可以增强小檗碱的抗菌活 性 ${ }^{[16]}$. Lee 等 ${ }^{[17]}$ 报道大风子素可能是新的 Wnt 抑制剂并 且在 $\beta$-catenin 介导的信号通路中具有信号调节的潜力.

大风子素类化合物在植物中的含量比较少, 所以对 这类化合物的结构修饰的报道也比较少. 最近, Maiti 等 ${ }^{[18]}$ 在次大风子素中引入异噁唑和异噁唑酮, 并且测 试了其抗癌活性(文章中描述的是大风子素, 而实际上
是次大风子素). 考虑到上述两类黄酮木质素结构比较 类似, 正如 Huang 等 ${ }^{[19]}$ 和 Gažák 等 ${ }^{[20]}$ 所采取的策略, 通 过合成手段实现由水飞蓟宾向大风子素结构, 将会有效 地大量制备大风子素类化合物. 在水飞蓟宾的 23 位羟 基碘代的实验中, 我们发现如果改变三苯基膦、碘单质 和咪唑三种试剂的物质的量之比, 可以在完成 23 位碘 取代的同时, 实现由水飞蓟宾向次大风子素的结构转 化. 考虑到黄酮木质素类化合物的生物利用度都比较 低，而酰胺类基团易与生物大分子形成氢键，增强与受 体的结合能力, 我们推测接入酰胺类基团的大风子素类 衍生物可能会有较好的生物活性表现, 因此在通过碘代 得到次大风子素的 23 位碘代物之后, 将碘基团转化为 酰胺类基团, 并测试其抗癌活性. 本文将介绍通过该方 法制备 15 个次大风子素的酰胺类衍生物, 以及它们的 抗癌活性评价.

\section{1 结果与讨论}

\section{1 目标化合物的合成}

采用三苯基膦、碘单质和咪唑在二氯甲烷和四氢呋 喃的混合溶液中与水飞蓟宾在室温下反应(Scheme 1). 观察产物的 ${ }^{1} \mathrm{H}$ NMR 谱, 可以发现代表 2-H, 3-OH, 23-OH 信号的处于 $\delta 5.08,4.92$ 和 5.80 三处的峰已经消 失. 代表 3-H 的信号从 $\delta 4.61$ 位移至 $\delta 6.89$, 并且由 $\mathrm{dd}$ 峰转变为单峰. 这表明 C-3 位上的羟基已和 C- 2 氢脱水 形成双键. 另外 C-23 位的两个氢信号由 $\delta 3.33,3.54$ 位 移至 $\delta 3.04$ 和 3.38, 同时 ${ }^{13} \mathrm{C}$ NMR 谱图中 C-23 的信号 从 $\delta 60.94$ 位移至 $\delta 5.31$, 表明 C-23 位的羟基转化为碘. 通过这些信息，可以推测成功得到了 C-23 位碘代的次 大风子素，即中间体 $\mathbf{I}$.

有关醇的脱氧反应, 前人有不少的报道, 比如 Barton-McCombie 去氧反应中, 先将醇转化为硫代羰基

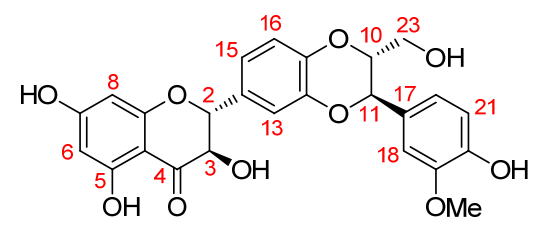

1a, silybin $A$

silybin (1): 1:1 mixture of

silybin A and silybin $B$<smiles>COc1cc(C2Oc3cc(-c4cc(=O)c5c(O)cc(O)cc5o4)ccc3OC2CO)ccc1O</smiles>

3, hydnocarpin D<smiles>COc1cc([C@H]2Oc3cc([C@@H]4Oc5cc(O)cc(O)c5C(=O)[C@H]4O)ccc3OC2CO)ccc1O</smiles>

1b, silybin B<smiles>COc1cc(/C=C(\CO)c2cc([C@@H]3Oc4cc(-c5cc(=O)c6c(O)cc(O)cc6o5)ccc4O[C@@H]3CO)cc(OC)c2O)ccc1O</smiles>

4, hydnowightin<smiles>COc1cc([C@H]2Oc3ccc(-c4cc(=O)c5c(O)cc(O)cc5o4)cc3O[C@H]2CO)ccc1O</smiles><smiles>COc1cc(C2C(c3cc(=O)c4c(O)cc(O)cc4o3)Cc3cc(O)c(O)cc3C2CO)ccc1OCCOCCOCCO</smiles>

5, neohydnocarpin

图 1 水飞蓟宾和大风子素类化合物化学结构

Figure 1 Chemical structures of sylibins and hydnocarpins 


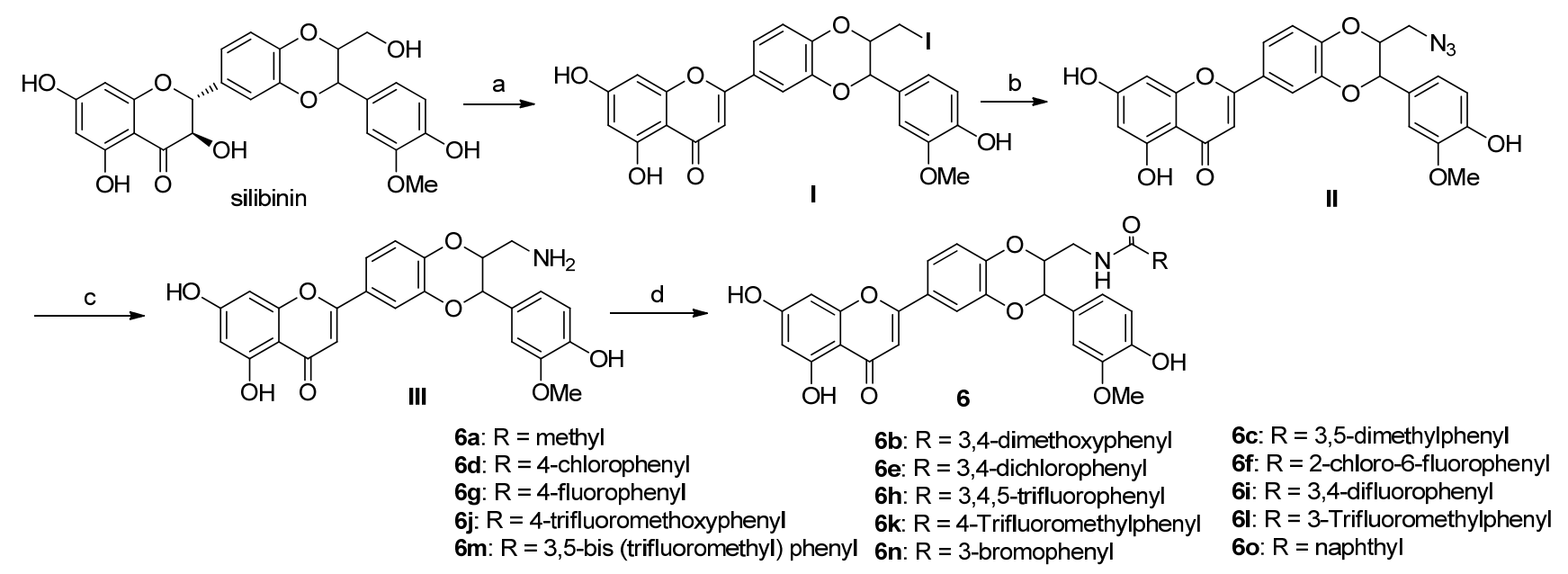

Reagents and conditions: (a) $\mathrm{Ph}_{3} \mathrm{P}, \mathrm{I}_{2}$, imidazole, $\mathrm{CH}_{2} \mathrm{Cl}_{2} / \mathrm{THF}$, r.t.; (b) $\mathrm{DMF}, \mathrm{NaN}_{3}$, r.t.; (c) $\mathrm{Ph}_{3} \mathrm{P}, \mathrm{THF} / \mathrm{H}_{2} \mathrm{O}(V: V=20: 1)$, r.t.; (d) Acyl chloride, $\mathrm{Et}_{3} \mathrm{~N}, \mathrm{THF}$, r.t.

图式 1 目标化合物的合成路线

Scheme 1 Synthetic procedure of the target compounds

中间体, 然后用 $\mathrm{Bu}_{3} \mathrm{SnH}$ 处理, 经自由基断裂得到醇的 脱羟基产物 ${ }^{[21]}$. Zhang 等 ${ }^{[22]} ⿺_{2}$ 现, 将醇转化为亚磷酸酯 化合物, 然后经磷酰基自由基过程, 也可高效地脱氧, 其中的氢来自反应溶剂. 我们设想在这一反应中, 水飞 蓟宾的 3 位羟基可能先转化为三苯基鏻鎓离子, 后者经 $\beta$-氢消去得到烯烃. 但具体的机理尚有待深入探索.

第二步反应中, 中间体 I 与叠氮化钠在 $N, N$-二甲基 甲酰胺(DMF)中常温下反应得到中间体 II, 之后中间体 II 的叠氮基在四氢呋喃/水溶液中被三苯基膦还原为氨 基, 得到中间体 III. 最后含胺基的中间体 III 与不同的 酰氯反应得到了 C-23 位酰胺取代的次大风子素的衍生 物 6a $\sim 60$ (Scheme 1), 产率在 40\% 50\%之间.

所合成的衍生物经 ${ }^{1} \mathrm{H} N \mathrm{NR},{ }^{13} \mathrm{C} N \mathrm{NR}$ 和 HRMS 分 析, 结果都与化合物的结构吻合. 因为所用的初始原料 商品水飞蓟宾是水飞蓟宾 $\mathrm{A}$ 和水飞蓟宾 $\mathrm{B}$ 的混合物(二 者比例约 $1: 1$ ), 在经 2,3-脱水反应后, 形成的产物是一 对约 $1: 1$ 的外消旋体, 因此这些衍生物不具有旋光性.

\section{2 生物活性评价}

实验中以重金属络合物顺铂(cisplatin)作为阳性对 照化合物, 用人非小细胞肺癌细胞(A549)、人乳腺癌细 胞(MCF-7)和宫颈癌细胞(HeLa) 三种癌细胞来评价 15 个 次大风子素的酰胺类衍生物对癌细胞的抗增殖活性. 同 时, 通过人体肝细胞(HL-7702)的增殖抑制情况来评价 合成化合物对正常细胞的毒性. 测试结果见(表 1).

结果显示大部分合成的衍生物对人体正常肝细胞 毒性较小. 除化合物 6g, 6h, 6n 和 6i 的 $\mathrm{IC}_{50}$ 值小于 40 $\mu \mathrm{mol} \cdot \mathrm{L}^{-1}$ 外, 其他化合物的 $\mathrm{IC}_{50}$ 值都大于 $40 \mu \mathrm{mol} \cdot \mathrm{L}^{-1}$, 其中化合物 6c, $6 \mathbf{e}$ 和 60 对于 HL-7702 的 $\mathrm{IC}_{50}$ 值均大于 $100 \mu \mathrm{mol} \cdot \mathrm{L}^{-1}$. 这表明大部分次大风子素的酰胺类衍生
物对正常肝细胞损伤较小, 具有较高的安全性. 进一步 抗癌细胞增殖活性测试结果表明, 大部分化合物对于人 乳腺癌细胞(MCF-7)和人非小细胞肺癌细胞(A549)都有 较好的抑制活性 $\left(\mathrm{IC}_{50}\right.$ 值小于 $\left.25 \mu \mathrm{mol} \cdot \mathrm{L}^{-1}\right)$. 这表明合成 的衍生物对癌细胞有增殖抑制效果.

化合物 6c 和 60 对于三种癌细胞几乎无效, 表明这 两个化合物没有抗增殖效果. 化合物 $6 \mathrm{~g}, 6 \mathrm{~h}, 6 \mathrm{i}, 6 \mathrm{k}$ 和 61 对 A549 具有很好的抑制活性, 其半数抑制浓度 $\left(\mathrm{IC}_{50}\right)$ 均 小于 $10 \mu \mathrm{mol} \cdot \mathrm{L}^{-1}$. 化合物 $\mathbf{6 b}$ 和 $\mathbf{6 f}$ 对于 HeLa 细胞抑制 活性很好, 尤其是化合物 $\mathbf{6 b}$ 的活性比阳性对照药顺铂 强四倍. 此外, 化合物 $6 \mathrm{~g}$ 和 $6 \mathrm{~m}$ 对 MCF-7 显示出潜在的 抑制活性. 化合物 6k 和 61 对 A549 细胞有很高的治疗指 数(即 $\mathrm{TI}$ 值在 10 以上), 化合物 6b 对 HL-7702 细胞的治 疗指数也非常好 (TI 值为 17.69).

由测试结果可知, 苯环上具有氟或三氟甲基取代的 苯甲酰胺类衍生物都表现出了较好的活性. 相比之下没 有氟或三氟甲基取代的苯甲酰胺类衍生物的活性则要 稍微弱一些. 这些结果提示未来可继续进行含氟苯甲酸 类衍生物的合成.

\section{2 结论}

介绍了一种新的合成方法, 将市售原料水飞蓟宾通 过碘代反应转化为 C-23 碘代的次大风子素, 之后将碘 代的次大风子素转化为不同酰胺取代的衍生物, 获得了 15 个次大风子素的酰胺取代的衍生物, 并测试了这些 衍生物的抗癌活性.

在对 A549 细胞的抗增殖活性试验中, 化合物 $\mathbf{6 g}$, $6 \mathbf{h}, 6 \mathbf{i}, 6 \mathbf{k}$ 和 61 显示出卓越的抑制活性 $\left(\mathrm{IC}_{50}\right.$ 均小于 10 $\mu \mathrm{mol} \cdot \mathrm{L}^{-1}$ ). 其中, 化合物 $6 \mathbf{h}, 6 \mathbf{i}, 6 \mathbf{k}$ 和 $6 \mathbf{1}$ 显示出略优于 
表 1 化合物 $\mathbf{6 a} \sim \mathbf{6 0}$ 的细胞毒性数据 $\left[\mathrm{IC}_{50} /\left(\mu \mathrm{mol} \cdot \mathrm{L}^{-1}\right)\right]$

Table 1 Cytotoxic activities $\left[\mathrm{IC}_{50} /\left(\mu \mathrm{mol} \cdot \mathrm{L}^{-1}\right)\right]$ of compounds $\mathbf{6 a} \sim \mathbf{6 o}$

\begin{tabular}{|c|c|c|c|c|c|c|c|}
\hline Compd. & HL-7702 ${ }^{a}$ & $\mathrm{~A} 549^{b}$ & $\mathrm{TI}^{c}$ & $\mathrm{HeLa}^{d}$ & $\mathrm{TI}^{e}$ & MCF $-7^{f}$ & $\mathrm{TI}^{g}$ \\
\hline $6 a$ & $47.64 \pm 1.53$ & $38.34 \pm 7.40$ & 1.24 & $23.67 \pm 2.76$ & 2.01 & $30.36 \pm 5.49$ & 1.57 \\
\hline $6 b$ & $89.80 \pm 1.37$ & $>100$ & & $5.08 \pm 0.39$ & 17.69 & $42.94 \pm 12.32$ & 2.09 \\
\hline $6 c$ & $>100$ & $>100$ & & $>100$ & & $>100$ & \\
\hline $6 d$ & $87.21 \pm 0.84$ & $16.01 \pm 2.67$ & 5.54 & $36.30 \pm 1.00$ & 2.44 & $20.68 \pm 2.11$ & 4.29 \\
\hline $6 e$ & $>100$ & $23.92 \pm 0.34$ & $>4.18$ & $>100$ & & $31.68 \pm 10.02$ & $>3.16$ \\
\hline $6 f$ & $89.98 \pm 0.59$ & $14.58 \pm 0.65$ & 6.17 & $9.03 \pm 0.08$ & 9.96 & $30.07 \pm 14.88$ & 2.99 \\
\hline $6 \mathrm{~g}$ & $16.18 \pm 0.83$ & $9.64 \pm 0.88$ & 1.68 & $25.46 \pm 1.19$ & 0.64 & $9.20 \pm 3.03$ & 1.76 \\
\hline $6 h$ & $30.06 \pm 1.61$ & $8.76 \pm 0.38$ & 3.43 & $20.90 \pm 2.17$ & 1.44 & $10.94 \pm 1.18$ & 2.75 \\
\hline $6 \mathbf{i}$ & $5.92 \pm 0.17$ & $7.96 \pm 1.87$ & 0.74 & $22.25 \pm 9.77$ & 0.27 & $11.73 \pm 1.55$ & 0.50 \\
\hline $6 \mathbf{j}$ & $77.03 \pm 15.70$ & $12.81 \pm 1.49$ & 6.01 & $41.48 \pm 1.77$ & 1.86 & $14.07 \pm 2.47$ & 5.48 \\
\hline $6 k$ & $90.21 \pm 1.43$ & $8.32 \pm 1.50$ & 10.84 & $23.20 \pm 3.69$ & 3.89 & $20.05 \pm 4.78$ & 4.50 \\
\hline 61 & $87.09 \pm 3.09$ & $8.25 \pm 1.57$ & 10.56 & $24.40 \pm 6.66$ & 3.57 & $16.49 \pm 0.97$ & 5.28 \\
\hline $6 \mathrm{~m}$ & $40.74 \pm 3.76$ & $14.93 \pm 0.7$ & 2.73 & $26.39 \pm 2.78$ & 1.54 & $9.61 \pm 1.08$ & 4.24 \\
\hline $6 n$ & $38.95 \pm 1.59$ & $15.51 \pm 1.82$ & 2.51 & $50.03 \pm 3.26$ & 0.78 & $31.91 \pm 0.48$ & 1.22 \\
\hline 60 & $>100$ & $>100$ & & $>100$ & & $>100$ & \\
\hline Cisplatin & $25.69 \pm 6.09$ & $8.95 \pm 0.42$ & & $20.66 \pm 0.54$ & & $13.78 \pm 0.08$ & \\
\hline
\end{tabular}

${ }^{a} \mathrm{HL} 7702$ normal human liver cells; ${ }^{b} \mathrm{~A} 549$ human prostate cancer cells; ${ }^{c}$ therapeutic index (TI), calculated on the $\mathrm{IC}_{50}$ of $\mathrm{HL} 7702$ normal human liver cells versus the $\mathrm{IC}_{50}$ of A549 line; ${ }^{d}$ HeLa cervical cancer cells; ${ }^{e}$ therapeutic index, calculated on the $\mathrm{IC}_{50}$ of $\mathrm{HL} 7702$ normal human liver cells versus the $\mathrm{IC}_{50}$ of HeLa line; ${ }^{f}$ MCF-7 human breast cancer cells; ${ }^{g}$ therapeutic index, calculated on the $\mathrm{IC}_{50}$ of $\mathrm{HL} 7702$ normal human liver cells versus the $\mathrm{IC}_{50}$ of $\mathrm{MCF}-7$ line.

阳性药顺铂的抑制活性. 化合物 $6 \mathbf{k}$ 和 61 在这 5 个化合 物中的治疗指数最高( TI 值在 10 以上). 化合物 $\mathbf{6 b}$ 和 $\mathbf{6 f}$ 对人宫颈癌细胞 $(\mathrm{HeLa})$ 的 $\mathrm{IC}_{50}$ 值均在 $10 \mu \mathrm{mol} \cdot \mathrm{L}^{-1}$ 以下, 而阳性对照药顺铂的 $\mathrm{IC}_{50}$ 值大于 $20 \mu \mathrm{mol} \cdot \mathrm{L}^{-1}$, 可见这 两个化合物对人宫颈癌细胞(HeLa)的抑制活性优于阳 性对照药顺铂, 其中化合物 $\mathbf{6 b}$ 的 $\mathrm{IC}_{50}$ 为 $5.08 \mu \mathrm{mol} \cdot \mathrm{L}^{-1}$, 同时其 TI 值为 17.69. 对于人乳腺癌细胞(MCF-7)细胞, 化合物 6g, 6h, 6i, 6m 呈现出了比阳性对照药顺铂更好 的抑制活性.

综上所述, 所合成的化合物对三种人体癌细胞呈现 出很好的抑制活性. 活性较好的衍生物, 多数是酰胺取 代基的苯环上具有氟或三氟甲基取代基, 因此可以推测 含氟的酰胺取代基对次大风子素抗癌活性有较大提升.

通过初步活性测试结果可以知道, 这些化合物对多 种癌症疾病具有潜在的应用价值, 因此有必要进一步深 入研究它们对癌细胞的抑制活性. 之后的研究将在探索 这些衍生物的抗癌机理的同时, 也将合成更多的含氟的 酰胺类衍生物, 以期得到具有更强抗癌活性的次大风子 素衍生物.

\section{3 实验部分}

水飞蓟宾购买自上海思域化工科技有限公司. 三苯 基膦购买自上海阿拉丁生化科技股份有限公司. 碘购买 自北京伊诺凯科技有限公司. 咪唑购买自成都科隆化学 品有限公司. 其他溶剂均使用分析纯.

核磁共振为 Varian 公司 INOVA-400 型(TMS 为内 标). 熔点由 Buchi B-540 型熔点仪测得. 高分辨质谱仪
为 AB SCIEX QSTAR Elite 四级杆飞行质谱仪. 薄层色 谱(TLC)选用 Merk Salica Gel $60 \mathrm{~F}_{254}$ plates 或青岛海洋 $\mathrm{GF}_{254}$ 硅胶板, 于紫外灯下观察. 柱层析硅胶 200 300 目. 其他常用化学试剂均为分析纯, 除特别说明外, 未 经处理直接使用.

\section{1 中间体 I, II 和 III 的合成}

将水飞蓟宾(2.41 g, $5 \mathrm{mmol}$ )溶于 $20 \mathrm{~mL}$ 四氢呋喃 中, 加入 $200 \mathrm{~mL}$ 二氯甲烷作为溶剂, 之后加入三苯基 膦(3.93 g, $15 \mathrm{mmol})$, 碘(5.08 g, $20 \mathrm{mmol})$, 咪唑(1.7 g, $25 \mathrm{mmol})$, 在室温下搅拌 $3 \mathrm{~h}$ 后用饱和亚硫酸钠溶液淬 灭反应, 之后向反应液中加入 $300 \mathrm{~mL}$ 水, 并用二氯甲 烷萃取 $(100 \mathrm{~mL} \times 3)$. 有机相合并后用无水硫酸钠干燥, 后浓缩得到粗产物, 粗产物用柱层析(石油醚/乙酸乙酯, $V: V=1: 1)$ 纯化, 得到 $1.49 \mathrm{~g}$ 黄色粉末, 即中间体 5,7二羟基-2-(3-(4-羟基-3-甲氧基苯基)-2-(碘代甲基)-2,3-二 羟基苯并 $[b][1,4]$ 二啞英-6-基)-4H-色烯-4-酮(I), 产率 52\%. m.p. 202 $203{ }^{\circ} \mathrm{C} ;{ }^{1} \mathrm{H}$ NMR (400 MHz, DMSO- $d_{6}$ ) $\delta: 12.90(\mathrm{~s}, 1 \mathrm{H}), 10.89(\mathrm{~s}, 1 \mathrm{H}), 9.31(\mathrm{~s}, 1 \mathrm{H}), 7.71(\mathrm{~d}, J=$ $2.2 \mathrm{~Hz}, 1 \mathrm{H}), 7.66$ (dd, $J=8.6,2.2 \mathrm{~Hz}, 1 \mathrm{H}), 7.16$ (d, $J=8.6$ $\mathrm{Hz}, 1 \mathrm{H}), 7.10$ (d, $J=1.9 \mathrm{~Hz}, 1 \mathrm{H}), 6.94$ (dd, $J=8.2,1.9 \mathrm{~Hz}$, $1 \mathrm{H}), 6.90$ (s, 1H), 6.84 (d, $J=8.2 \mathrm{~Hz}, 1 \mathrm{H}), 6.51$ (d, $J=2.1$ $\mathrm{Hz}, 1 \mathrm{H}), 6.19$ (d, $J=2.1 \mathrm{~Hz}, 1 \mathrm{H}), 4.84$ (d, $J=7.5 \mathrm{~Hz}, 1 \mathrm{H})$, 4.32 (ddd, $J=8.1,5.4,3.1 \mathrm{~Hz}, 1 \mathrm{H}), 3.80$ (s, 3H), 3.39 $3.34(\mathrm{~m}, 2 \mathrm{H}), 3.03(\mathrm{dd}, J=11.5,5.4 \mathrm{~Hz}, 1 \mathrm{H}) ;{ }^{13} \mathrm{C} \mathrm{NMR}$ $\left(100 \mathrm{MHz}, \mathrm{DMSO}-d_{6}\right) \delta: 182.2,164.7,163.1,161.8,157.7$, $148.2,147.9,146.5,144.3,126.4,124.3,121.3,120.7$, 
117.8, 115.8, 115.5, 112.1, 104.4, 104.2, 99.3, 94.5, 79.6, 75.1, 56.1, 5.7; HRMS (ESI) calcd for $\mathrm{C}_{25} \mathrm{H}_{18} \mathrm{IO}_{8}[\mathrm{M}-\mathrm{H}]$ 573.0052 , found 573.0048 .

将中间体 I ( $3 \mathrm{~g}, 5.23 \mathrm{mmol})$ 溶于 $50 \mathrm{~mL} \mathrm{~N}, N$-二甲基 甲酰胺中, 加入 $\mathrm{NaN}_{3}(679.4 \mathrm{mg}, 10.45 \mathrm{mmol})$, 在室温 下搅拌 $12 \mathrm{~h}$ 后加入 $300 \mathrm{~mL}$ 乙酸乙酯稀释反应液, 用水 $(100 \mathrm{~mL} \times 6)$ 洗去体系中的 $N, N$-二甲基甲酰胺. 有机相 用无水硫酸钠干燥后浓缩, 得到 $2.7 \mathrm{~g}$ 粗产物, 即中间体 2-(2-(叠氮甲基)-3-(4-羟基-3-甲氧基苯基)-2,3-二羟基苯 并 $[b][1,4]$ 二噁英-6-基)-5,7-二羟基- $4 H$-色烯-4-酮(II). 粗 产物未经纯化直接进行下一步反应.

将中间体 II (3.24 g, $6.63 \mathrm{mmol})$ 溶于混合溶剂四氢 呋喃/水 $(V: V=20: 1,50 \mathrm{~mL})$ 中, 加入三苯基膦(3.472 $\mathrm{g}, 13.25 \mathrm{mmol}$ ), 在室温下搅拌 $12 \mathrm{~h}$, 反应过程中有大量 沉淀产生. 过滤出沉淀, 并用二氯甲烷洗去沉淀中的杂 质, 得到 $2.4 \mathrm{~g}$ 粗产物, 即中间体 2-(2-(氨基甲基)-3-(4羟基-3-甲氧基苯基)-2,3-二羟基苯并 $[b][1,4]$ 二噁英-6基)-5,7-二羟基- $4 H$-色烯-4-酮(III). 由于产物很难溶解, 很难对其进行纯化, 未做进一步处理直接进行下一步反 应. 中间体 III 为黄色粉末, m.p. 204 206 ${ }^{\circ} \mathrm{C}$; HRMS (ESI) calcd for $\mathrm{C}_{25} \mathrm{H}_{20} \mathrm{NO}_{8}[\mathrm{M}-\mathrm{H}]^{-}$462.1194, found 462.1191 .

\section{2 化合物 $6 a \sim 60$ 的合成}

将中间体 III (100 mg, $0.22 \mathrm{mmol})$ 溶于 $10 \mathrm{~mL}$ 四氢 呋喃中, 溶液中加入不同的酰氯 $(0.22 \mathrm{mmol})$ 和三乙胺 $(71.3 \mathrm{mg}, 0.55 \mathrm{mmol}$ )在室温中搅拌 $1 \mathrm{~h}$ 后加水淬灭反应, 反应液用二氯甲烷 $(10 \mathrm{~mL} \times 3)$ 萃取. 有机相合并, 用无 水硫酸钠干燥后浓缩, 所得粗产物用柱层析 (二氯甲烷) 甲醇, $V: V=120: 1)$ 纯化后得到目标化合物 6 .

$N$-((6-(5,7-二羟基-4-氧代-4H-色烯-2-基)-3-(4-羟基3 -甲氧基苯基)-2,3-二羟基苯并 $[b][1,4]$ 二硻英-2-基)甲 基)乙酰胺(6a): 黄色粉末, 产率 42.6\%. m.p. 207 $209{ }^{\circ} \mathrm{C} ;{ }^{1} \mathrm{H}$ NMR (400 MHz, DMSO- $\left.d_{6}\right) \delta: 12.89$ (s, $1 \mathrm{H}$ ), $10.88(\mathrm{~s}, 1 \mathrm{H}), 9.21(\mathrm{~s}, 1 \mathrm{H}), 8.01(\mathrm{t}, J=5.4 \mathrm{~Hz}, 1 \mathrm{H}), 7.68$ (d, $J=2.2 \mathrm{~Hz}, 1 \mathrm{H}), 7.64$ (dd, $J=8.6,2.2 \mathrm{~Hz}, 1 \mathrm{H}), 7.11$ (d, $J=8.6 \mathrm{~Hz}, 1 \mathrm{H}), 7.02(\mathrm{~d}, J=1.9 \mathrm{~Hz}, 1 \mathrm{H}), 6.91 \sim 6.84(\mathrm{~m}$, 2H), $6.82(\mathrm{~d}, J=8.1 \mathrm{~Hz}, 1 \mathrm{H}), 6.50(\mathrm{~d}, J=2.1 \mathrm{~Hz}, 1 \mathrm{H}), 6.19$ (d, $J=2.1 \mathrm{~Hz}, 1 \mathrm{H}), 4.93$ (d, $J=7.8 \mathrm{~Hz}, 1 \mathrm{H}), 4.40$ (td, $J=$ 7.8, $3.4 \mathrm{~Hz}, 1 \mathrm{H}), 3.79(\mathrm{~s}, 3 \mathrm{H}), 3.25 \sim 3.10(\mathrm{~m}, 2 \mathrm{H}), 1.82(\mathrm{~s}$, $3 \mathrm{H}) ;{ }^{13} \mathrm{C}$ NMR (100 MHz, DMSO- $\left.d_{6}\right) \delta$ : 182.1, 169.8, $164.7,163.2,161.8,157.7,148.0,147.7,146.6,144.3$, $127.0,124.1,121.0,120.5,117.8,115.8,115.5,112.2$, 104.3, 104.2, 99.3, 94.5, 77.0, 76.5, 56.0, 39.8, 22.8; HRMS (ESI) calcd for $\mathrm{C}_{27} \mathrm{H}_{22} \mathrm{NO}_{9}[\mathrm{M}-\mathrm{H}]^{-}$504.1300, found 504.1299.
$N$-((6-(5,7-二羟基-4-氧代-4H-色烯-2-基)-3-(4-羟基3 -甲氧基苯基)-2,3-二羟基苯并 $[b][1,4]$ 二啞英-2-基)甲 基)-3,4-二甲氧基苯甲酰胺(6b): 黄色粉末, 产率 55.4\%. m.p. $151 \sim 153{ }^{\circ} \mathrm{C}$; ${ }^{1} \mathrm{H}$ NMR (400 MHz, DMSO- $\left.d_{6}\right) \delta$ : 12.89 (s, 1H), 10.86 (s, 1H), 9.20 (s, 1H), 8.43 (t, $J=5.4$ $\mathrm{Hz}, 1 \mathrm{H}), 7.69$ (d, $J=2.2 \mathrm{~Hz}, 1 \mathrm{H}), 7.63(\mathrm{dd}, J=8.6,2.2 \mathrm{~Hz}$, $1 \mathrm{H}), 7.44(\mathrm{dd}, J=8.5,2.2 \mathrm{~Hz}, 1 \mathrm{H}), 7.38(\mathrm{~d}, J=2.2 \mathrm{~Hz}$, $1 \mathrm{H}), 7.11(\mathrm{~d}, J=8.5 \mathrm{~Hz}, 1 \mathrm{H}), 7.07(\mathrm{~d}, J=2.0 \mathrm{~Hz}, 1 \mathrm{H}), 7.00$ (d, $J=8.6 \mathrm{~Hz}, 1 \mathrm{H}), 6.92(\mathrm{dd}, J=8.1,2.0 \mathrm{~Hz}, 1 \mathrm{H}), 6.88(\mathrm{~s}$, $1 \mathrm{H}), 6.83(\mathrm{~d}, J=8.1 \mathrm{~Hz}, 1 \mathrm{H}), 6.51(\mathrm{~d}, J=2.1 \mathrm{~Hz}, 1 \mathrm{H}), 6.19$ (d, $J=2.1 \mathrm{~Hz}, 1 \mathrm{H}), 5.02(\mathrm{~d}, J=7.5 \mathrm{~Hz}, 1 \mathrm{H}), 4.56(\mathrm{td}, J=$ 7.5, $3.9 \mathrm{~Hz}, 1 \mathrm{H}), 3.80 \sim 3.77(\mathrm{~m}, 9 \mathrm{H}), 3.50 \sim 3.37$ (m, $2 \mathrm{H}$ ); ${ }^{13} \mathrm{C}$ NMR (100 MHz, DMSO- $\left.d_{6}\right) \delta: 181.8,166.0,164.2$, $162.8,161.4,157.3,151.2,148.1,147.6,147.2,146.1$, $143.9,126.7,126.3,123.7,120.6,120.5,120.2,117.4$, 115.4, 115.2, 111.9, 110.8, 110.6, 103.9, 103.8, 98.9, 94.1, 76.9, 75.9, 55.7, 55.6, 55.5, 40.4; HRMS (ESI) calcd for $\mathrm{C}_{34} \mathrm{H}_{28} \mathrm{NO}_{11}[\mathrm{M}-\mathrm{H}]^{-}$626.1668, found 626.1666 .

$N$-((6-(5,7-二羟基-4-氧代-4H-色烯-2-基)-3-(4-羟基3 -甲氧基苯基)-2,3-二羟基苯并 $[b][1,4]$ 二噁英-2-基)甲 基)-3,5-二甲基苯甲酰胺(6c): 黄色粉末，产率 48.3\%. m.p. $258 \sim 260{ }^{\circ} \mathrm{C}$; ${ }^{1} \mathrm{H}$ NMR (400 MHz, DMSO- $\left.d_{6}\right) \delta$ : $12.90(\mathrm{~s}, 1 \mathrm{H}), 10.85(\mathrm{~s}, 1 \mathrm{H}), 9.20(\mathrm{~s}, 1 \mathrm{H}), 8.35$ (t, $J=5.5$ $\mathrm{Hz}, 1 \mathrm{H}), 7.69(\mathrm{~d}, J=2.2 \mathrm{~Hz}, 1 \mathrm{H}), 7.63(\mathrm{dd}, J=8.6,2.2 \mathrm{~Hz}$, $1 \mathrm{H}), 7.36(\mathrm{~s}, 2 \mathrm{H}), 7.14(\mathrm{~s}, 1 \mathrm{H}), 7.11(\mathrm{~d}, J=8.6 \mathrm{~Hz}, 1 \mathrm{H})$, $7.07(\mathrm{~d}, J=2.0 \mathrm{~Hz}, 1 \mathrm{H}), 6.92(\mathrm{dd}, J=8.2,2.0 \mathrm{~Hz}, 1 \mathrm{H})$, $6.88(\mathrm{~s}, 1 \mathrm{H}), 6.83(\mathrm{~d}, J=8.2 \mathrm{~Hz}, 1 \mathrm{H}), 6.51(\mathrm{~d}, J=2.1 \mathrm{~Hz}$, $1 \mathrm{H}), 6.19(\mathrm{~d}, J=2.1 \mathrm{~Hz}, 1 \mathrm{H}), 5.02(\mathrm{~d}, J=7.6 \mathrm{~Hz}, 1 \mathrm{H}), 4.56$ (td, $J=7.6,4.0 \mathrm{~Hz}, 1 \mathrm{H}), 3.78(\mathrm{~s}, 3 \mathrm{H}), 3.54 \sim 3.44(\mathrm{~m}, 1 \mathrm{H})$, $3.40 \sim 3.34(\mathrm{~m}, 1 \mathrm{H}), 2.30(\mathrm{~s}, 6 \mathrm{H}) ;{ }^{13} \mathrm{C}$ NMR $(100 \mathrm{MHz}$, DMSO- $\left.d_{6}\right) \delta: 181.8,166.8,164.2,162.8,161.4,157.3$, $147.7,147.3,146.2,143.9,137.3$ (2C), 134.2, 132.4, $126.7,125.0$ (2C), 123.7, 120.7, 120.2, 117.5, 115.4, 115.1, 111.9, 104.0, 103.8, 98.9, 94.1, 76.9, 75.8, 55.7, 40.4, 20.8 (2C); HRMS (ESI) calcd for $\mathrm{C}_{34} \mathrm{H}_{28} \mathrm{NO}_{9}[\mathrm{M}-\mathrm{H}]$ 594.1770, found 594.1770.

4-氯- $N$-((6-(5,7-二羟基-4-氧代-4H-色烯-2-基)-3-(4羟基-3-甲氧基苯基)-2,3-二羟基苯并 $[b][1,4]$ 二氧基-2基)甲基)苯甲酰胺(6d): 黄色粉末, 产率 53.6\%. m.p. $183 \sim 185{ }^{\circ} \mathrm{C} ;{ }^{1} \mathrm{H}$ NMR (400 MHz, DMSO- $d_{6}$ ) $\delta: 12.89$ (s, $1 \mathrm{H}), 10.92(\mathrm{~s}, 1 \mathrm{H}), 9.20(\mathrm{~s}, 1 \mathrm{H}), 8.64(\mathrm{t},=5.4 \mathrm{~Hz}, 1 \mathrm{H})$, $7.81(\mathrm{~d}, J=8.6 \mathrm{~Hz}, 2 \mathrm{H}), 7.69(\mathrm{~d}, J=2.2 \mathrm{~Hz}, 1 \mathrm{H}), 7.63(\mathrm{dd}$, $J=8.5,2.2 \mathrm{~Hz}, 1 \mathrm{H}), 7.52(\mathrm{~d}, J=8.6 \mathrm{~Hz}, 2 \mathrm{H}), 7.11$ (d, $J=$ $8.5 \mathrm{~Hz}, 1 \mathrm{H}), 7.06(\mathrm{~d}, J=2.0 \mathrm{~Hz}, 1 \mathrm{H}), 6.91(\mathrm{dd}, J=8.3,2.0$ $\mathrm{Hz}, 1 \mathrm{H}), 6.87$ (s, 1H), 6.82 (d, $J=8.3 \mathrm{~Hz}, 1 \mathrm{H}), 6.50$ (d, $J=$ 
$2.1 \mathrm{~Hz}, 1 \mathrm{H}), 6.19(\mathrm{~d}, J=2.1 \mathrm{~Hz}, 1 \mathrm{H}), 5.02(\mathrm{~d}, J=7.6 \mathrm{~Hz}$, $1 \mathrm{H}), 4.57$ (td, $J=7.6,3.7 \mathrm{~Hz}, 1 \mathrm{H}), 3.77$ (s, 3H), 3.48 $3.38(\mathrm{~m}, 2 \mathrm{H}) ;{ }^{13} \mathrm{C}$ NMR (100 MHz, DMSO- $\left.d_{6}\right) \delta: 182.2$, $165.9,164.8,163.2,161.8,157.8,148.1,147.7,146.6$, 144.3, 136.5, 133.3, 129.7 (2C), 128.7 (2C), 127.1, 124.2, 121.1, 120.6, 117.9, 115.9, 115.6, 112.3, 104.2, 99.4, 94.5, 77.2, 76.2, 66.8, 56.1, 40.9; HRMS (ESI) calcd for $\mathrm{C}_{32} \mathrm{H}_{23} \mathrm{ClNO}_{9}[\mathrm{M}-\mathrm{H}]^{-} \quad 600.1067$, found 600.1070 .

3,4-二氯- $N$-( (6- $(5,7$ - 二羟基-4-氧代- $4 H$ - 色烯-2基)-3-(4-羟基-3-甲氧基苯基)-2,3-二羟基苯并 $[b][1,4]$ 二 氧基-2-基)甲基)苯甲酰胺(6e): 黄色粉末，产率 48.7\%. m.p. $181 \sim 183{ }^{\circ} \mathrm{C}$; ${ }^{1} \mathrm{H}$ NMR (400 MHz, DMSO- $d_{6}$ ) $\delta$ : 12.89 (s, 1H), 10.85 (s, 1H), 9.19 (s, 1H), 8.76 (t, $J=5.5$ $\mathrm{Hz}, 1 \mathrm{H}), 8.02(\mathrm{~d}, J=2.0 \mathrm{~Hz}, 1 \mathrm{H}), 7.77(\mathrm{dd}, J=8.4,2.0 \mathrm{~Hz}$, $2 \mathrm{H}), 7.73(\mathrm{~d}, J=8.4 \mathrm{~Hz}, 2 \mathrm{H}), 7.69(\mathrm{~d}, J=2.2 \mathrm{~Hz}, 1 \mathrm{H}), 7.63$ (dd, $J=8.6,2.2 \mathrm{~Hz}, 1 \mathrm{H}), 7.11(\mathrm{~d}, J=8.6 \mathrm{~Hz}, 1 \mathrm{H}), 7.06(\mathrm{~d}$, $J=2.0 \mathrm{~Hz}, 1 \mathrm{H}), 6.91(\mathrm{dd}, J=8.3,2.0 \mathrm{~Hz}, 1 \mathrm{H}), 6.87$ (s, $1 \mathrm{H}), 6.82(\mathrm{~d}, J=8.3 \mathrm{~Hz}, 1 \mathrm{H}), 6.50(\mathrm{~d}, J=2.1 \mathrm{~Hz}, 1 \mathrm{H}), 6.19$ (d, $J=2.1 \mathrm{~Hz}, 1 \mathrm{H}), 5.02(\mathrm{~d}, J=7.6 \mathrm{~Hz}, 1 \mathrm{H}), 4.57$ (td, $J=$ 7.6, $4.1 \mathrm{~Hz}, 1 \mathrm{H}), 3.78(\mathrm{~s}, 3 \mathrm{H}), 3.54 \sim 3.38(\mathrm{~m}, 2 \mathrm{H}) ;{ }^{13} \mathrm{C}$ NMR $\left(100 \mathrm{MHz}\right.$, DMSO- $\left.d_{6}\right) \delta: 181.8,164.3,162.8,161.4$, $157.3,147.6,147.3,146.1,143.9,134.4,134.1,131.2$, $130.6,129.3,127.6,126.6,123.8,120.7,120.2,117.5$, 115.4, 115.1, 111.9, 104.0, 103.8, 98.9, 94.1, 76.8, 75.7, 55.7, 54.9, 40.5; HRMS (ESI) calcd for $\mathrm{C}_{32} \mathrm{H}_{22} \mathrm{Cl}_{2} \mathrm{NO}_{9}$ $[\mathrm{M}-\mathrm{H}]^{-}$634.0677, found 634.0677.

2-氯- $N$-((6-(5,7-二羟基-4-氧代- $4 H$-色烯-2-基)-3-(4羟基-3-甲氧基苯基)-2,3-二羟基苯并 $[b][1,4]$ 二嚚英-2基)甲基)-6-氟苯甲酰胺(6f): 黄色粉末, 产率 51.2\%. m.p. $177 \sim 179{ }^{\circ} \mathrm{C} ;{ }^{1} \mathrm{H}$ NMR (400 MHz, DMSO- $d_{6}$ ) $\delta$ : 12.89 (s, 1H), $10.86(\mathrm{~s}, 1 \mathrm{H}), 9.25$ (s, 1H), 9.00 (t, $J=5.4$ $\mathrm{Hz}, 1 \mathrm{H}), 7.70(\mathrm{~d}, J=2.2 \mathrm{~Hz}, 1 \mathrm{H}), 7.65(\mathrm{dd}, J=8.6,2.2 \mathrm{~Hz}$, $1 \mathrm{H}), 7.48(\mathrm{td}, J=8.2,6.1 \mathrm{~Hz}, 1 \mathrm{H}), 7.37(\mathrm{~d}, J=8.2 \mathrm{~Hz}$, $1 \mathrm{H}), 7.30(\mathrm{t}, J=8.6 \mathrm{~Hz}, 1 \mathrm{H}), 7.11 \sim 7.05(\mathrm{~m}, 2 \mathrm{H}), 6.93(\mathrm{dd}$, $J=8.1,2.0 \mathrm{~Hz}, 1 \mathrm{H}), 6.88(\mathrm{~s}, 1 \mathrm{H}), 6.85(\mathrm{~d}, J=8.1 \mathrm{~Hz}, 1 \mathrm{H})$, $6.51(\mathrm{~d}, J=2.1 \mathrm{~Hz}, 1 \mathrm{H}), 6.20(\mathrm{~d}, J=2.1 \mathrm{~Hz}, 1 \mathrm{H}), 5.00$ (d, $J=7.9 \mathrm{~Hz}, 1 \mathrm{H}), 4.52(\mathrm{td}, J=7.9,4.9 \mathrm{~Hz}, 1 \mathrm{H}), 3.80(\mathrm{~s}, 3 \mathrm{H})$, $3.42(\mathrm{t}, J=5.2 \mathrm{~Hz}, 2 \mathrm{H}) ;{ }^{13} \mathrm{C}$ NMR (100 MHz, DMSO- $\left.d_{6}\right)$ $\delta: 181.8,164.3,162.8,162.0,161.4,159.9 / 157.5(\mathrm{~d}, J=$ $247.5 \mathrm{~Hz}), 157.3,147.7,147.3,146.2,143.8,131.3,131.0$, $126.5,126.1,125.3,123.7,120.6,120.2,117.4,115.5$, 115.1, 114.7, 114.5, 111.8, 103.8, 98.9, 94.1, 76.2, 75.7, 55.7, 30.7; HRMS (ESI) calcd for $\mathrm{C}_{32} \mathrm{H}_{22} \mathrm{CIFNO}_{9}[\mathrm{M}-\mathrm{H}]^{-}$ 618.0973, found 618.0967.

$N$-((6-(5,7-二羟基-4-氧代-4 $H$-色烯-2-基)-3-(4-羟基-
3-甲氧基苯基)-2,3-二羟基苯并 $[b][1,4]$ 二硻英-2-基)甲 基)-4-氟苯甲酰胺 $(6 \mathrm{~g})$ : 黄色粉末, 产率 52.4\%. m.p. 204 206 ${ }^{\circ} \mathrm{C} ;{ }^{1} \mathrm{H}$ NMR (400 MHz, DMSO- $d_{6}$ ) $\delta: 12.90$ (s, $1 \mathrm{H}), 10.88(\mathrm{~s}, 1 \mathrm{H}), 9.23(\mathrm{~s}, 1 \mathrm{H}), 8.61(\mathrm{t}, J=5.5 \mathrm{~Hz}, 1 \mathrm{H})$, 7.87 (ddd, $J=8.9,5.6,2.8 \mathrm{~Hz}, 2 \mathrm{H}), 7.70(\mathrm{~d}, J=2.2 \mathrm{~Hz}$, $1 \mathrm{H}), 7.64(\mathrm{dd}, J=8.6,2.2 \mathrm{~Hz}, 1 \mathrm{H}), 7.33 \sim 7.24(\mathrm{~m}, 2 \mathrm{H})$, $7.11(\mathrm{~d}, J=8.6 \mathrm{~Hz}, 1 \mathrm{H}), 7.07$ (d, $J=1.9 \mathrm{~Hz}, 1 \mathrm{H}), 6.95 \sim$ $6.88(\mathrm{~m}, 2 \mathrm{H}), 6.82(\mathrm{~d}, J=8.1 \mathrm{~Hz}, 1 \mathrm{H}), 6.51(\mathrm{~d}, J=2.1 \mathrm{~Hz}$, $1 \mathrm{H}), 6.19(\mathrm{~d}, J=2.1 \mathrm{~Hz}, 1 \mathrm{H}), 5.03(\mathrm{~d}, J=7.7 \mathrm{~Hz}, 1 \mathrm{H}), 4.57$ (td, $J=7.7,3.9 \mathrm{~Hz}, 1 \mathrm{H}), 3.77$ (s, $3 \mathrm{H}), 3.46 \sim 3.36(\mathrm{~m}, 2 \mathrm{H})$; ${ }^{13} \mathrm{C}$ NMR (101 MHz, DMSO- $\left.d_{6}\right) \delta: 182.2,165.6,165.5 /$ $163.1(\mathrm{~d}, J=248.6 \mathrm{~Hz}), 164.7,163.2,161.8,157.8,148.1$, $147.7,146.6,144.3,131.0,130.4,130.3,127.1,124.1$, $121.1,120.6,117.9,115.9,115.7,115.6,115.5,112.3$, 104.4, 104.2, 99.3, 94.5, 77.2, 70.2, 56.1, 40.8; HRMS (ESI) calcd for $\mathrm{C}_{32} \mathrm{H}_{23} \mathrm{FNO}_{9}[\mathrm{M}-\mathrm{H}]^{-}$584.1362, found 584.1362 .

$N$-((6-(5,7-二羟基-4-氧代- $4 H$-色烯-2-基)-3-(4-羟基3-甲氧基苯基)-2,3-二羟基苯并 $[b][1,4]$ 二嚚英-2-基)甲 基)-3,4,5-三氟苯甲酰胺(6h): 黄色粉末, 产率 48.2\%. m.p. $185 \sim 186{ }^{\circ} \mathrm{C} ;{ }^{1} \mathrm{H}$ NMR (400 MHz, DMSO- $d_{6}$ ) $\delta$ : 12.89 (s, 1H), $10.86(\mathrm{~s}, 1 \mathrm{H}), 9.18$ (s, 1H), 8.73 (t, $J=5.4$ $\mathrm{Hz}, 1 \mathrm{H}), 7.77 \sim 7.68(\mathrm{~m}, 3 \mathrm{H}), 7.69(\mathrm{~d}, J=2.2 \mathrm{~Hz}, 2 \mathrm{H})$, $7.63(\mathrm{dd}, J=8.6,2.2 \mathrm{~Hz}, 1 \mathrm{H}), 7.12(\mathrm{~d}, J=8.6 \mathrm{~Hz}, 1 \mathrm{H})$, $7.05(\mathrm{~d}, J=2.0 \mathrm{~Hz}, 1 \mathrm{H}), 6.90(\mathrm{dd}, J=8.2,2.0 \mathrm{~Hz}, 1 \mathrm{H})$, $6.88(\mathrm{~s}, 1 \mathrm{H}), 6.81(\mathrm{~d}, J=8.2 \mathrm{~Hz}, 1 \mathrm{H}), 6.50(\mathrm{~d}, J=2.1 \mathrm{~Hz}$, $1 \mathrm{H}), 6.19(\mathrm{~d}, J=2.1 \mathrm{~Hz}, 1 \mathrm{H}), 5.02(\mathrm{~d}, J=7.7 \mathrm{~Hz}, 1 \mathrm{H}), 4.56$ (td, $J=7.7,4.2 \mathrm{~Hz}, 1 \mathrm{H}), 3.77$ (s, $3 \mathrm{H}), 3.5 \sim 3.39$ (m, $2 \mathrm{H}$ ); ${ }^{13} \mathrm{C}$ NMR (100 MHz, DMSO- $\left.d_{6}\right) \delta: 182.2,164.7,163.7$, $163.2,161.8,157.8,151.5 / 149.1(\mathrm{~d}, J=235.0 \mathrm{~Hz}, 2 \mathrm{C})$, $148.0,147.8,147.7 / 145.6$ (d, $J=217.8 \mathrm{~Hz}), 146.5,144.3$, $130.8,127.0,124.2,121.1,120.6,117.9,115.8,115.6$, $112.9,112.9,112.3,104.4,104.2,99.3,94.5,77.2,76.0$, 56.1, 41.0; HRMS (ESI) calcd for $\mathrm{C}_{32} \mathrm{H}_{21} \mathrm{~F}_{3} \mathrm{NO}_{9}[\mathrm{M}-\mathrm{H}]^{-}$ 620.1174 , found 620.1170 .

$\mathrm{N}$-((6-(5,7-二羟基-4-氧代-4H-色烯-2-基)-3-(4-羟基3-甲氧基苯基)-2,3-二羟基苯并 $[b][1,4]$ 二噁英-2-基)甲 基)-3,4-二氟苯甲酰胺(6i): 黄色粉末, 产率 52.8\%. m.p. $209 \sim 210{ }^{\circ} \mathrm{C} ;{ }^{1} \mathrm{H}$ NMR (400 MHz, DMSO- $d_{6}$ ) $\delta: 12.89$ (s, $1 \mathrm{H}), 10.86(\mathrm{~s}, 1 \mathrm{H}), 9.19(\mathrm{~s}, 1 \mathrm{H}), 8.67$ (t, $J=5.2 \mathrm{~Hz}, 1 \mathrm{H})$, 7.83 (ddd, $J=11.6,7.8,2.2 \mathrm{~Hz}, 1 \mathrm{H}), 7.76 \sim 7.66(\mathrm{~m}, 2 \mathrm{H})$, $7.63(\mathrm{dd}, J=8.6,2.2 \mathrm{~Hz}, 1 \mathrm{H}), 7.53(\mathrm{td}, J=11.6,7.8 \mathrm{~Hz}$, $1 \mathrm{H}), 7.11(\mathrm{~d}, J=8.6 \mathrm{~Hz}, 1 \mathrm{H}), 7.06(\mathrm{~d}, J=2.0 \mathrm{~Hz}, 1 \mathrm{H}), 6.91$ (dd, $J=8.1,2.0 \mathrm{~Hz}, 1 \mathrm{H}), 6.87$ (s, 1H), $6.82(\mathrm{~d}, J=8.1 \mathrm{~Hz}$, $1 \mathrm{H}), 6.50(\mathrm{~d}, J=2.1 \mathrm{~Hz}, 1 \mathrm{H}), 6.19(\mathrm{~d}, J=2.1 \mathrm{~Hz}, 1 \mathrm{H}), 5.02$ 
(d, $J=7.6 \mathrm{~Hz}, 1 \mathrm{H}), 4.56$ (td, $J=7.6,4.0 \mathrm{~Hz}, 1 \mathrm{H}), 3.77$ (s, $3 \mathrm{H}), 3.51 \sim 3.38(\mathrm{~m}, 2 \mathrm{H}) ;{ }^{13} \mathrm{C}$ NMR $\left(100 \mathrm{MHz}\right.$, DMSO- $\left.d_{6}\right)$ $\delta: 181.8,164.3,164.3,162.8,161.4,157.3,152.5 / 150.3$ (d, $J=218.9 \mathrm{~Hz}), 150.0 / 147.9$ (d, $J=214.5 \mathrm{~Hz}), 147.6,147.3$, $146.1,143.9,131.5,126.6,124.8,123.8,120.7,120.2$, 117.4, 116.8, 116.6, 115.4, 115.1, 111.9, 104.0, 103.8, 98.9, 94.1, 76.8, 75.7, 55.7, 40.5; HRMS (ESI) calcd for $\mathrm{C}_{32} \mathrm{H}_{22} \mathrm{~F}_{2} \mathrm{NO}_{9}[\mathrm{M}-\mathrm{H}]^{-}$602.1268, found 602.1268.

$N$-((6-(5,7-二羟基-4-氧代-4H-色烯-2-基)-3-(4-羟基3 -甲氧基苯基)-2,3-二羟基苯并 $[b][1,4]$ 二噁英-2-基)甲 基)-3-(三氟甲氧基)苯甲酰胺 (6jj): 黄色粉末, 产率 46.5\%. m.p. $139 \sim 140{ }^{\circ} \mathrm{C} ;{ }^{1} \mathrm{H}$ NMR $(400 \mathrm{MHz}$, DMSO- $\left.d_{6}\right) \delta: 12.89(\mathrm{~s}, 1 \mathrm{H}), 10.84(\mathrm{~s}, 1 \mathrm{H}), 9.20(\mathrm{~s}, 1 \mathrm{H})$, $8.77(\mathrm{t}, J=5.5 \mathrm{~Hz}, 1 \mathrm{H}), 7.85(\mathrm{dt}, J=7.8,1.5 \mathrm{~Hz}, 1 \mathrm{H}), 7.76$ (t, $J=1.5 \mathrm{~Hz}, 1 \mathrm{H}), 7.70(\mathrm{~d}, J=2.2 \mathrm{~Hz}, 1 \mathrm{H}), 7.67 \sim 7.56$ (m, 2H), $7.54(\mathrm{dt}, J=7.8,1.5 \mathrm{~Hz}, 1 \mathrm{H}), 7.11(\mathrm{~d}, J=8.6 \mathrm{~Hz}$, $1 \mathrm{H}), 7.07(\mathrm{~d}, J=2.0 \mathrm{~Hz}, 1 \mathrm{H}), 6.92(\mathrm{dd}, J=8.1,2.0 \mathrm{~Hz}$, $1 \mathrm{H}), 6.88(\mathrm{~s}, 1 \mathrm{H}), 6.83(\mathrm{~d}, J=8.1 \mathrm{~Hz}, 1 \mathrm{H}), 6.51$ (d, $J=2.1$ $\mathrm{Hz}, 1 \mathrm{H}), 6.19(\mathrm{~d}, J=2.1 \mathrm{~Hz}, 1 \mathrm{H}), 5.04(\mathrm{~d}, J=7.6 \mathrm{~Hz}, 1 \mathrm{H})$, 4.58 (td, $J=7.6,3.7 \mathrm{~Hz}, 1 \mathrm{H}), 3.78(\mathrm{~s}, 3 \mathrm{H}), 3.52 \sim 3.38(\mathrm{~m}$, $2 \mathrm{H}) ;{ }^{13} \mathrm{C}$ NMR (100 MHz, DMSO- $\left.d_{6}\right) \delta: 181.8,164.9$, $164.3,162.8,161.4,157.3,148.3,147.6,147.3,146.1$, $143.9,136.3,130.5,126.7,126.4,126.3 / 124.0 / 121.3 / 118.8$ (dd, $J=257.7,241.6 \mathrm{~Hz}), 123.8,123.7,120.7,120.2$, 119.8, 117.5, 115.4, 115.2, 111.9, 104.0, 103.8, 98.9, 94.1, 76.7, 75.7, 55.7, 40.5; HRMS (ESI) calcd for $\mathrm{C}_{33} \mathrm{H}_{23} \mathrm{~F}_{3}$ $\mathrm{NO}_{10}[\mathrm{M}-\mathrm{H}]^{-}$650.1280, found 650.1279.

$N$-((6-(5,7-二羟基-4-氧代-4 $H$-色烯-2-基)-3-(4-羟基3 -甲氧基苯基)-2,3-二羟基苯并 $[b][1,4]$ 二硻英-2-基)甲 基)-4-(三氟甲基)苯甲酰胺(6k): 黄色粉末,产率 53.4\%. m.p. $178 \sim 179{ }^{\circ} \mathrm{C}$; ${ }^{1} \mathrm{H}$ NMR (400 MHz, DMSO- $d_{6}$ ) $\delta$ : 12.89 (s, 1H), 10.87 (s, 1H), 9.20 (s, 1H), 8.80 (t, $J=5.6$ $\mathrm{Hz}, 1 \mathrm{H}), 7.99$ (d, $J=8.1 \mathrm{~Hz}, 2 \mathrm{H}), 7.83(\mathrm{~d}, J=8.1 \mathrm{~Hz}, 2 \mathrm{H})$, $7.69(\mathrm{~d}, J=2.2 \mathrm{~Hz}, 1 \mathrm{H}), 7.63(\mathrm{dd}, J=8.6,2.2 \mathrm{~Hz}, 1 \mathrm{H})$, 7.11 (d, $J=8.6 \mathrm{~Hz}, 1 \mathrm{H}), 7.08$ (d, $J=2.0 \mathrm{~Hz}, 1 \mathrm{H}), 6.93$ (dd, $J=8.2,2.0 \mathrm{~Hz}, 1 \mathrm{H}), 6.87(\mathrm{~s}, 1 \mathrm{H}), 6.83(\mathrm{~d}, J=8.2 \mathrm{~Hz}, 1 \mathrm{H})$, $6.50(\mathrm{~d}, J=2.1 \mathrm{~Hz}, 1 \mathrm{H}), 6.19(\mathrm{~d}, J=2.1 \mathrm{~Hz}, 1 \mathrm{H}), 5.03$ (d, $J=7.6 \mathrm{~Hz}, 1 \mathrm{H}), 4.59(\mathrm{td}, J=7.6,3.9 \mathrm{~Hz}, 1 \mathrm{H}), 3.78(\mathrm{~s}, 3 \mathrm{H})$, $3.52 \sim 3.40(\mathrm{~m}, 2 \mathrm{H}) ;{ }^{13} \mathrm{C}$ NMR (100 MHz, DMSO- $\left.d_{6}\right) \delta$ : $181.7,165.4,164.3,162.8,161.4,157.3,147.7,147.3$, $146.1,143.9,137.9,131.3,131.0 / 128.1 / 125.3 / 122.6(\mathrm{dd}$, $J=285.9,273.8 \mathrm{~Hz}), 128.2(2 \mathrm{C}), 126.7,125.3,125.2$, $123.8,120.7,120.2,117.4,115.5,115.1,111.9,104.0$, 103.8, 98.9, 94.1, 76.8, 75.7, 55.7, 40.4; HRMS (ESI) calcd for $\mathrm{C}_{33} \mathrm{H}_{23} \mathrm{~F}_{3} \mathrm{NO}_{9}[\mathrm{M}-\mathrm{H}]^{-}$634.1330, found
634.1327.

$N$-((6-(5,7-二羟基-4-氧代-4H-色烯-2-基)-3-(4-羟基3-甲氧基苯基)-2,3-二羟基苯并 $[b][1,4]$ 二啞英-2-基)甲 基)-3-(三氟甲基)苯甲酰胺(61): 黄色粉末, 产率 51.5\%. m.p. $194 \sim 195{ }^{\circ} \mathrm{C} ;{ }^{1} \mathrm{H}$ NMR (400 MHz, DMSO- $\left.d_{6}\right) \delta$ : 12.89 (s, 1H), 10.85 (s, 1H), 9.19 (s, 1H), 8.86 (t, $J=5.6$ $\mathrm{Hz}, 1 \mathrm{H}), 8.14$ (s, 1H), $8.10(\mathrm{~d}, J=7.9 \mathrm{~Hz}, 1 \mathrm{H}), 7.90$ (d, $J=$ $7.9 \mathrm{~Hz}, 1 \mathrm{H}), 7.77 \sim 7.68(\mathrm{~m}, 2 \mathrm{H}), 7.63(\mathrm{dd}, J=8.6,2.3 \mathrm{~Hz}$, $1 \mathrm{H}), 7.11(\mathrm{~d}, J=8.6 \mathrm{~Hz}, 1 \mathrm{H}), 7.07$ (d, $J=2.0 \mathrm{~Hz}, 1 \mathrm{H}), 6.93$ (dd, $J=8.1,2.0 \mathrm{~Hz}, 1 \mathrm{H}), 6.88(\mathrm{~s}, 1 \mathrm{H}), 6.82(\mathrm{~d}, J=8.1 \mathrm{~Hz}$, $1 \mathrm{H}), 6.51(\mathrm{~d}, J=2.1 \mathrm{~Hz}, 1 \mathrm{H}), 6.19(\mathrm{~d}, J=2.1 \mathrm{~Hz}, 1 \mathrm{H}), 5.04$ (d, $J=7.6 \mathrm{~Hz}, 1 \mathrm{H}), 4.60$ (td, $J=7.6,3.8 \mathrm{~Hz}, 1 \mathrm{H}), 3.78$ (s, $3 \mathrm{H}), 3.52 \sim 3.38(\mathrm{~m}, 2 \mathrm{H}),{ }^{13} \mathrm{C}$ NMR $\left(100 \mathrm{MHz}\right.$, DMSO- $\left.d_{6}\right)$ $\delta: 182.2,165.5,164.7,163.3,161.9,157.8,148.1,147.8$, $146.6,144.3,135.4,131.8,130.1,129.7,128.4,128.3 /$ $127.1 / 124.4 / 123.1$ (dd, $J=149.4,126.0 \mathrm{~Hz}$ ), 127.1, 124.3, $124.2,121.1,120.6,117.9,115.9,115.6,112.4,104.4$, 104.2, 99.4, 94.5, 77.2, 76.2, 56.1, 40.9; HRMS (ESI) calcd for $\mathrm{C}_{33} \mathrm{H}_{23} \mathrm{~F}_{3} \mathrm{NO}_{9}[\mathrm{M}-\mathrm{H}]^{-}$634.1330, found 634.1329 .

$\mathrm{N}$-((6-(5,7-二羟基-4-氧代-4H-色烯-2-基)-3-(4-羟基3-甲氧基苯基)-2,3-二羟基苯并 $[b][1,4]$ 二啞英-2-基)甲 基)-3,5-双 (三氟甲基)苯甲酰胺 (6m): 黄色粉末, 产率 50.7\%. m.p. $172 \sim 173{ }^{\circ} \mathrm{C}$; ${ }^{1} \mathrm{H}$ NMR (400 MHz, DMSO$\left.d_{6}\right) \delta: 12.89(\mathrm{~s}, 1 \mathrm{H}), 10.87(\mathrm{~s}, 1 \mathrm{H}), 9.12(\mathrm{t}, J=5.5 \mathrm{~Hz}, 1 \mathrm{H})$, 8.44 (s, 2H), 8.31 (s, 1H), $7.70(\mathrm{~d}, J=2.3 \mathrm{~Hz}, 1 \mathrm{H}), 7.63$ (dd, $J=8.6,2.3 \mathrm{~Hz}, 1 \mathrm{H}), 7.12(\mathrm{~d}, J=8.6 \mathrm{~Hz}, 1 \mathrm{H}), 7.07$ (d, $J=2.0 \mathrm{~Hz}, 1 \mathrm{H}), 6.92(\mathrm{dd}, J=8.2,2.0 \mathrm{~Hz}, 1 \mathrm{H}), 6.87(\mathrm{~s}$, $1 \mathrm{H}), 6.81$ (d, $J=8.2 \mathrm{~Hz}, 1 \mathrm{H}), 6.50$ (d, $J=2.1 \mathrm{~Hz}, 1 \mathrm{H}), 6.19$ (d, $J=2.1 \mathrm{~Hz}, 1 \mathrm{H}), 5.05(\mathrm{~d}, J=7.6 \mathrm{~Hz}, 1 \mathrm{H}), 4.61(\mathrm{td}, J=$ 7.6, $3.9 \mathrm{~Hz}, 1 \mathrm{H}), 3.77(\mathrm{~s}, 3 \mathrm{H}), 3.60 \sim 3.43(\mathrm{~m}, 2 \mathrm{H}) ;{ }^{13} \mathrm{C}$ NMR $\left(100 \mathrm{MHz}\right.$, DMSO- $\left.d_{6}\right) \delta: 181.7,164.4,163.6,162.8$, $161.4,157.3,147.6,147.3,146.0,143.9,136.2,130.6$, $130.2,128.1,128.0,127.9 / 125.0 / 121.8 / 117.5$ (dd, $J=$ $311.3,302.3 \mathrm{~Hz}, 2 \mathrm{C}), 126.6,124.9,123.8,120.7,120.2$, 118.8, 115.4, 115.2, 111.9, 104.0, 103.7, 98.9, 94.1, 76.8, 75.7, 55.6, 40.6; HRMS (ESI) calcd for $\mathrm{C}_{34} \mathrm{H}_{22} \mathrm{~F}_{6} \mathrm{NO}_{9}$ $[\mathrm{M}-\mathrm{H}]^{-}$702.1204, found 702.1200 .

3-溴- $N$-((6-(5,7-二羟基-4-氧代- $4 H$-色烯-2-基)-3-(4羟基-3-甲氧基苯基)-2,3-二羟基苯并 $[b][1,4]$ 二噁英-2基)甲基)苯甲酰胺(6n): 黄色粉末, 产率 47.8\%. m.p. 197 $199{ }^{\circ} \mathrm{C} ;{ }^{1} \mathrm{H}$ NMR (400 MHz, DMSO- $d_{6}$ ) $\delta: 12.90$ (s, $1 \mathrm{H}), 10.86(\mathrm{~s}, 1 \mathrm{H}), 9.20(\mathrm{~s}, 1 \mathrm{H}), 8.70(\mathrm{t}, J=5.5 \mathrm{~Hz}, 1 \mathrm{H})$, 7.98 (t, $J=1.9 \mathrm{~Hz}, 1 \mathrm{H}), 7.80$ (dt, $J=8.0,1.3 \mathrm{~Hz}, 1 \mathrm{H}), 7.73$ (ddd, $J=8.0,1.9,1.3 \mathrm{~Hz}, 1 \mathrm{H}), 7.69(\mathrm{~d}, J=2.3 \mathrm{~Hz}, 1 \mathrm{H})$, 
$7.63(\mathrm{dd}, J=8.6,2.3 \mathrm{~Hz}, 1 \mathrm{H}), 7.42(\mathrm{t}, J=8.0 \mathrm{~Hz}, 1 \mathrm{H}), 7.11$ $(\mathrm{d}, J=8.6 \mathrm{~Hz}, 1 \mathrm{H}), 7.07$ (d, $J=2.0 \mathrm{~Hz}, 1 \mathrm{H}), 6.92$ (dd, $J=$ $8.1,2.0 \mathrm{~Hz}, 1 \mathrm{H}), 6.87(\mathrm{~s}, 1 \mathrm{H}), 6.83(\mathrm{~d}, J=8.1 \mathrm{~Hz}, 1 \mathrm{H})$, 6.50 (d, $J=2.1 \mathrm{~Hz}, 1 \mathrm{H}), 6.19$ (d, $J=2.1 \mathrm{~Hz}, 1 \mathrm{H}), 5.03$ (d, $J=7.6 \mathrm{~Hz}, 1 \mathrm{H}), 4.57$ (td, $J=7.6,3.8 \mathrm{~Hz}, 1 \mathrm{H}), 3.78$ (s, 3H), $3.56 \sim 3.34(\mathrm{~m}, 2 \mathrm{H}) ;{ }^{13} \mathrm{C}$ NMR (100 MHz, DMSO-d $\left.d_{6}\right) \delta$ : $181.8,165.0,164.3,162.8,161.4,157.3,147.6,147.3$, $146.1,143.9,136.3,134.0,130.5,130.0,126.7,126.5$, $123.7,121.6,120.7,120.2,117.5,115.4,115.1,111.9$, 104.0, 103.8, 98.9, 94.1, 76.7, 75.7, 55.7, 40.4; HRMS (ESI) calcd for $\mathrm{C}_{32} \mathrm{H}_{23} \mathrm{BrNO}_{9}[\mathrm{M}-\mathrm{H}]^{-}$644.0562, found 644.0562 .

$N$-((6-(5,7-二羟基-4-氧代-4H-色烯-2-基)-3-(4-差基3 -甲氧基苯基)-2,3-二羟基苯并 $[b][1,4]$ 二噁英-2-基)甲 基)-2-菜酰胺(6o): 黄色粉末, 产率 50.2\%. m.p. 176 $177{ }^{\circ} \mathrm{C} ;{ }^{1} \mathrm{H}$ NMR (400 MHz, DMSO-d $) \delta: 12.90$ (s, 1H), $10.86(\mathrm{~s}, 1 \mathrm{H}), 9.22(\mathrm{~s}, 1 \mathrm{H}), 8.67(\mathrm{t}, J=5.5 \mathrm{~Hz}, 1 \mathrm{H}), 8.35$ $(\mathrm{d}, J=1.8 \mathrm{~Hz}, 1 \mathrm{H}), 8.06 \sim 7.93(\mathrm{~m}, 3 \mathrm{H}), 7.87(\mathrm{dd}, J=8.6$, $1.8 \mathrm{~Hz}, 1 \mathrm{H}), 7.71(\mathrm{~d}, J=2.2 \mathrm{~Hz}, 1 \mathrm{H}), 7.64(\mathrm{dd}, J=8.6,2.2$ $\mathrm{Hz}, 1 \mathrm{H}), 7.60$ (ddd, $J=6.8,4.1,1.8 \mathrm{~Hz}, 2 \mathrm{H}), 7.13$ (d, $J=$ $8.6 \mathrm{~Hz}, 1 \mathrm{H}), 7.10$ (d, $J=2.0 \mathrm{~Hz}, 1 \mathrm{H}), 6.95$ (dd, $J=8.2,2.0$ $\mathrm{Hz}, 1 \mathrm{H}), 6.88(\mathrm{~s}, 1 \mathrm{H}), 6.85$ (d, $J=8.2 \mathrm{~Hz}, 1 \mathrm{H}), 6.51$ (d, $J=$ $2.1 \mathrm{~Hz}, 1 \mathrm{H}), 6.20(\mathrm{~d}, J=2.1 \mathrm{~Hz}, 1 \mathrm{H}), 5.07(\mathrm{~d}, J=7.6 \mathrm{~Hz}$, $1 \mathrm{H}), 4.63(\mathrm{td}, J=7.6,4.0 \mathrm{~Hz}, 1 \mathrm{H}), 3.79(\mathrm{~s}, 3 \mathrm{H}), 3.59 \sim$ $3.41(\mathrm{~m}, 2 \mathrm{H}) ;{ }^{13} \mathrm{C}$ NMR $\left(100 \mathrm{MHz}, \mathrm{DMSO}-d_{6}\right) \delta: 181.8$, $166.6,164.3,162.8,161.4,157.3,147.7,147.3,146.2$, $143.9,134.1,132.1,131.5,128.9,127.8,127.6(2 \mathrm{C})$, $127.5,126.8,126.7,124.2,123.7,120.6,120.2,117.5$, $115.5,115.2,112.0,104.0,103.8,98.9,94.1,76.9,75.8$, 55.7, 40.5; HRMS (ESI) calcd for $\mathrm{C}_{36} \mathrm{H}_{26} \mathrm{NO}_{9}[\mathrm{M}-\mathrm{H}]$ 616.1613 , found 616.1611 .

\section{3 细胞毒性实验}

将细胞接种到 96 孔板中, 用含有体积分数为 $10 \%$ 的胎牛血清的培液培养 $24 \mathrm{~h}$, 然后暴露于不同浓度的药 物中 $\left(100,10,1,0.1,0.01 \mathrm{~mol} \cdot \mathrm{L}^{-1}\right)$. 顺铂和二甲基亚砜 (DMSO)分别作为阳性对照和阴性对照. 孵育 $72 \mathrm{~h}$ 后, 将 $20 \mu \mathrm{L} /$ 孔的噻唑蓝(MTT) 溶液 $(5 \mathrm{mg} / \mathrm{mL}$, 用灭菌磷酸 盐缓冲液溶解)加入到每个孔中, 再孵育 $4 \mathrm{~h}$. 依次在每 个孔中加入 $100 \mu \mathrm{L}$ 溶解液 $(50 \mathrm{~g}$ 十二烷基硫酸钠, $25 \mathrm{~mL}$ 异丁醇, $0.5 \mathrm{~mL} \mathrm{HCL}$, 以超纯水定容至 $500 \mathrm{~mL}$ ), 以溶解 甲臜晶体. 溶解一夜后, 在 $570 \mathrm{~nm}$ 下用酶标仪测量每孔 吸光度(OD). 这些化合物的抑制率计算所使用的公式 为: 抑制率 $(\%)=\left(\mathrm{OD}_{\text {control }}-\mathrm{OD}_{\text {treated }}\right) / \mathrm{OD}_{\text {control }} \times 100 \%$. 用 $\mathrm{IC}_{50}$ 值评价这些化合物的活性.

\section{4 培养基和试剂}

原发性人肝 HL-7702 细胞购买自上海生命科学研 究所, MCF-7, A549 和 HeLa传代细胞购买自美国模式培 养物集存库(ATCC, 美国马里兰州洛克维尔市). HL7702 和 A549 细胞在洛斯维·帕克纪念研究所(RPMI) 1640 培养基中培养. HeLa 和 MCF-7 在达尔伯克改良伊 格尔培养基(DMEM)中培养，两种培养基辅以体积分数 为 $10 \%$ 的胎牛血清(FBS)和体积分数为 $1 \%$ 抗生素(青霉 素和链需素). 所有细胞均在 $37{ }^{\circ} \mathrm{C}$ 下在含有体积分数为 $5 \%$ 的 $\mathrm{CO}_{2}$ 的培养箱中培养.

辅助材料(Supporting Information) 化合物 $6 \mathbf{6 a} \sim 60$ 的 ${ }^{1} \mathrm{H}$ NMR 和 ${ }^{13} \mathrm{C}$ NMR 谱图. 这些材料可以免费从本刊网 站(http://sioc-journal.cn/)上下载.

\section{References}

[1] Abenavoli, L.; Capasso, R.; Milic, N.; Capasso, F. Phytother. Res. 2010, 24, 1423.

[2] Vogel, G.; Tuchweber, B.; Trost, W.; Mengs, U. Toxicol. Appl. Pharmacol. 1984, 73, 355.

[3] Švagera, Z.; Škottová, N.; Váňa, P.; Večeřa, R.; Urbánek, K.; Belejová, M.; Kosina, P.; Šimánek, V. Phytother. Res. 2003, 17, 524.

[4] Dai, J.-P.; Wu, L.-Q.; Li, R.; Zhao, X.-F.; Wan, Q.-Y.; Chen, X.-X.; Li, W.-Z.; Wang, G.-F.; Li, K.-S. Antimicrob. Agents Chemother. 2013, 57, 4433.

[5] Agarwal, R.; Agarwal, C.; Ichikawa, H.; Singh, R. P.; Aggarwal, B. B. Anticancer Res. 2006, 26, 4457.

[6] Kim, N. C.; Graf, T. N.; Sparacino, C. M.; Wani, M. C.; Wall, M. E. Org. Biomol. Chem. 2003, 1, 1684.

[7] Biedermann, D.; Vavř́íková, E.; Cvak, L.; Křen, V. Nat. Prod. Rep. 2014, 31, 1138.

[8] Guz, N. R.; Stermitz, F. R. J. Nat. Prod. 2000, 63, 1140.

[9] Wang, J. F.; Yin, G. F.; Zhou, X. J.; Su. J.; Li, Y.; Zhong, H. M.; Duan, G.; Cheng, Y. X. J. Asian Nat. Prod. Res. 2011, 13, 80.

[10] Sharma, D.; Ranganathan, K.; Parthasarathy, M.; Bhushan, B.; Seshadri, T. R. Planta Med. 1979, 37, 79.

[11] Parthasarathy, M. R.; Ranganathan, K. R.; Sharma, D. K. Phytochemistry 1979, 18, 506.

[12] Ranganathan, K. R.; Seshadri, T. R. Tetrahedron Lett. 1973, 14, 3481 .

[13] Sharma, D. K.; Hall, I. H. J. Nat. Prod. 1991, 54, 1298.

[14] Reddy, S. V.; Tiwari, A. K.; Kumar, U. S.; Rao, R. J.; Rao, J. M. Phytother. Res. 2005, 19, 277.

[15] Stermitz, F. R.; Beeson, T. D.; Mueller, P. J.; Hsiang, J. F.; Lewis, K. Biochem. Syst. Ecol. 2001, 29, 793.

[16] Stermitz, F. R.; Lorenz, P.; Tawara, J. N.; Zenewicz, L. A.; Lewis, K. Proc. Natl. Acad. Sci. U. S. A. 2000, 97, 1433.

[17] Lee, M. A.; Kim, W. K.; Park, H. J.; Kang, S. S.; Lee, S. K. Bioorg. Med. Chem. 2013, 23, 5511.

[18] Arya, J. S.; Joseph, M. M.; Sherin, D. R.; Nair, J. B.; Manojkumar, T. K.; Maiti, K. K. J. Med. Chem. 2019, 62, 8311.

[19] Huang, G.; Schramm, S.; Heilmann, J.; Biedermann, D.; Křen, V.; Decker, M. Beilstein J. Org. Chem. 2016, 12, 662.

[20] Vimberg, V.; Kuzma, M.; Stodůlková, E.; Novák, P.; Bednárová, L.; Šulc, M.; Gažák, R. J. Nat. Prod. 2015, 78, 2095.

[21] Myers, A. G.; Movassaghi, M.; Zheng, B. J. Am. Chem. Soc. 1997, 119,8572 .

[22] Zhang, L. M.; Koreeda, M. J. Am. Chem. Soc. 2004, 126, 13190.

(Zhao, C.) 